
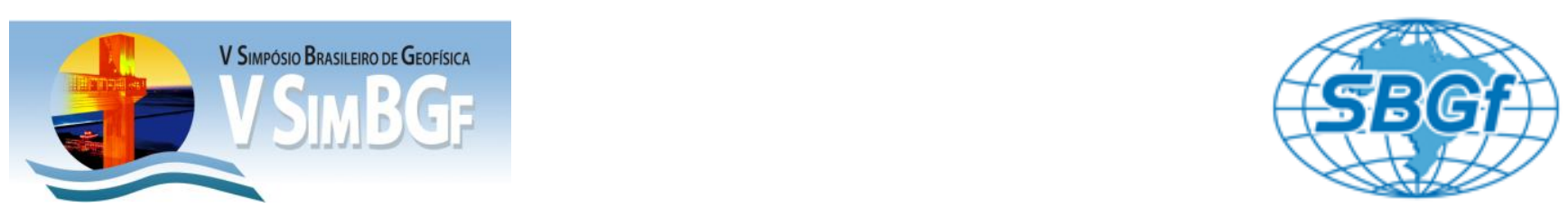

\title{
Estudo da espessura da crosta e razão Vp/Vs da Província Borborema, NE Brasil, através de funções do receptor.
}

Rosana M. do Nascimento*1, Jordi Julià ${ }^{1}$, Aderson F. Do Nascimento ${ }^{1}$, Joaquim M. Ferreira ${ }^{1}$

1-Programa de Pós-Graduação em Geodinâmica e Geofísica, Universidade Federal do Rio Grande do Norte, Natal/RN Brasil.

\section{Copyright 2012, SBGf - Sociedade Brasileira de Geofísica}

Este texto foi preparado para a apresentação no V Simpósio Brasileiro de Geofísica, Salvador, 27 a 29 de novembro de 2012. Seu conteúdo foi revisado pelo Comitê Técnico do V SimBGt, mas não necessariamente representa a opinião da SBGf ou de seus associados. É proibida a reprodução total ou parcial deste material para propósitos comerciais sem prévia autorização da SBGf.

\section{Resumo}

A Província Borborema, localizada no nordeste do Brasil, possui um embasamento de idade Pré- cambriana e um arcabouço tectônico estruturado no final do Neoproterozóico. Após a separação dos continentes SulAmericano e Africano no Cenozóico, o soerguimento do Planalto da Borborema e o magmatismo ao longo da linha Macau-Queimadas marcou a evolução da Província. Estudos independentes baseados em medidas gravimétricas propuseram que a crosta inferior sob a região do Planalto é mais espessa e tem valores anômalos da densidade, quando comparadas às demais regiões da Província. Nosso estudo investiga mudanças de espessura crustal e razão $\mathrm{Vp} / \mathrm{Vs}$ através de funções de receptor de eventos telessísmicos registrados em estações banda larga (Rede Sismográfica do Nordeste, RSisNE) e de período curto (Instituto Nacional de Ciência e Tecnologia de Estudos Tectônicos, INCT-ET) instaladas na Província. Os resultados mostram que, em geral, a espessura diminui do oeste para o leste da Província sem uma correlação clara com a razão Vp/Vs. $\mathrm{Na}$ região do Planalto, dois perfis em direção NNW-SSE e um perfil em direção NNE-SSW verificam a presença de uma crosta mais espessa no centro do Planalto. No entanto, um incremento significativo da razão $\mathrm{Vp} / \mathrm{Vs}$ com a espessura crustal não é observado.

\section{Introdução}

A Província Borborema do Nordeste do Brasil teve uma evolução tectônica e magmática complexa, desde a orogenia Brasiliana no final do Neoproterozóico ( 600 $\mathrm{Ma}$ ) até o final do Cenozóico, marcado por eventos magmáticos como os vulcanismos de Mecejana, Macau e Cabo (Mizusaki et al., 2002) e o soerguimento do Planalto da Borborema (Morais Neto et al., 2009). O Planalto possui um formato elíptico com alinhamento na direção NNE-SSW (Figura 1) e com altitudes que chegam a $1200 \mathrm{~m}$ na sua parte central e oeste, configurando a região mais elevada da Província.

Segundo Oliveira \& Medeiros (2012), as causas do soerguimento do Planalto estão associadas a um underplating magmático. $\mathrm{O}$ modelo propõe que correntes de convecção em pequena escala na borda da litosfera continental teriam produzido magma que haveria extrudido em pequena quantidade na área continental, de modo que uma quantidade significativa de material máfico teria ficado preso na base da crosta. Após isso, as interações entre rochas magmáticas e 0 manto circundante teria provocado deformações na crosta e por fim o soerguimento da região, que supõe-se ter ocorrido até que o planalto aplainasse e atingisse seu equilíbrio isostático.

O método de funções do receptor, o qual usa eventos telessísmicos, permite estimar a espessura crustal $\mathrm{H} \mathrm{e} \mathrm{a}$ razão $\mathrm{Vp} / \mathrm{Vs}$ localmente. Material máfico é caracterizado por razões $\mathrm{Vp} / \mathrm{Vs}$ maiores do que o material félsico (Christensen, 1996). Assim, essas estimativas na região do Planalto da Borborema nos possibilitam verificar a presença de material máfico na base da crosta. Os eventos utilizados neste trabalho foram registrados em quinze estações de banda larga da rede RSisNE e quinze estações de período curto da rede do INCT-ET, ambas recém-instaladas no Nordeste do Brasil. Usamos também resultados da estação RCBR, da rede global GSN, estimados por França et al. (2006).

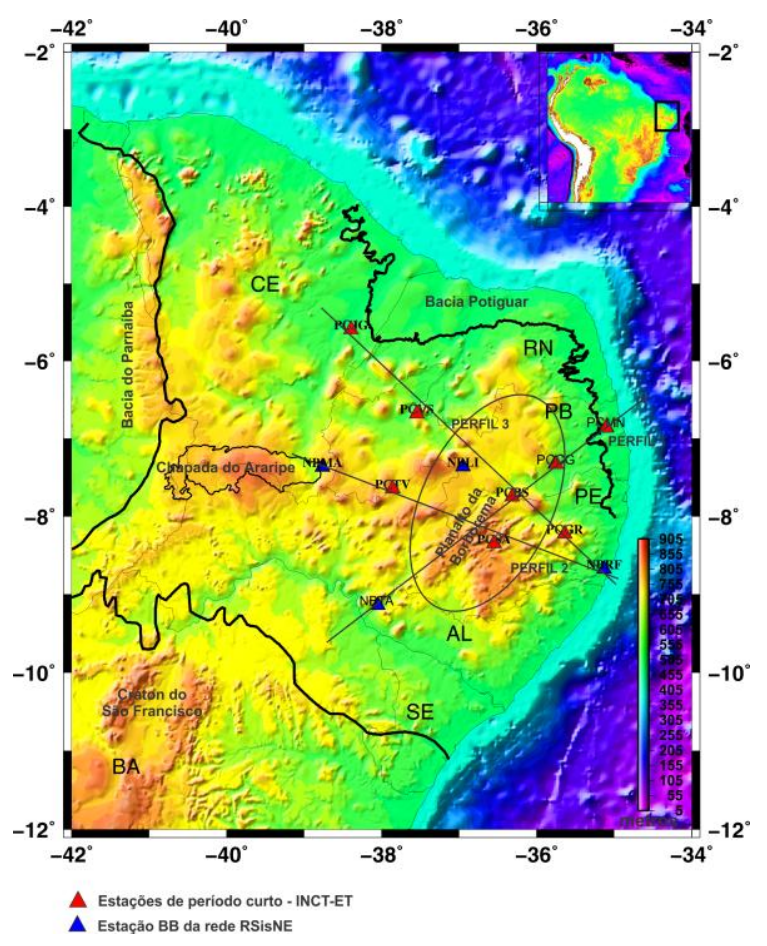

Figura 1: Topografia do Nordeste Brasileiro, destacando o Planalto da Borborema, chapada do Araripe, Cráton do São Francisco e bacias Potiguar e Parnaíba. Mapa também mostra os perfis feitos cruzando o Planalto. Perfil 1 (NNE-SSW), perfis 2 e 3 (NNW-SSE). 


\section{Função do receptor}

A função do receptor é uma série temporal calculada com os eventos telessísmicos registrados com uma distância epicentral de $30^{\circ}-90^{\circ}$ e tem sido um método muito utilizado para investigar as propriedades sísmicas da crosta (Julià \& Mejía, 2004; Zhu \& Kanamori, 2000). A técnica foi desenvolvida por Langston (1979) e considera que o sismograma tem informações relacionadas com o mecanismo da fonte, com a resposta instrumental e com a estrutura local sob a estação. Os registros são pela operação de deconvolução, expressa pelo quociente através de

$H(\omega)=\frac{I(\omega) S(\omega) D_{R}(\omega)}{I(\omega) S(\omega) D_{V}(\omega)}=\frac{D_{R}(\omega)}{D_{V}(\omega)}$,

onde $\omega$ é a frequência angular, $S(\omega)$ é o espectro de fonte, $H(\omega)$ é a transformada de Fourier da função de receptor e $D(\omega)$ é a estrutura sob a estação.

A função de receptor é constituída pela onda $P$ direta $e$ por ondas secundárias resultantes das conversões $P$ para S na Moho, como mostrado na Figura 2.
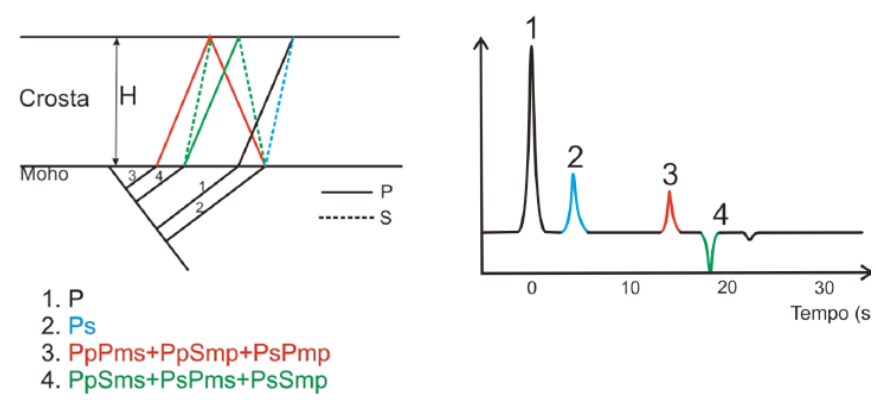

Figura 2: Trajetória de raios, transmissão e conversões em um modelo crustal, e função do receptor esquemática com as principais fases. (modificada de Julià et al. 2000).

\section{H-k Stacking}

Após o cálculo da função do receptor, é usado um algoritmo para estimar as razões $\mathrm{Vp} / \mathrm{Vs}$ e a espessura crustal H sob cada estação. O h-K stacking (Zhu \& Kanamori, 2000), soma as amplitudes das funções de receptor de acordo com o tempo de chegada de cada fase e são transformadas do domínio do tempo para o domínio H-k definido como:

$$
S(H, \kappa)=\omega_{1} r\left(t_{1}\right)+\omega_{2} r\left(t_{2}\right)+\omega_{3} r\left(t_{3}\right)
$$

onde $r(\mathrm{t})$ é a função de receptor radial; $\mathrm{t} 1, \mathrm{t} 2, \mathrm{t} 3$ são os tempos de chegada das principais convesões $\mathrm{P}$ para $\mathrm{S}, \mathrm{K}$ é a razão vp/vs e a $\mathrm{H}$ é a espessura crustal; wi são os pesos, o qual a somatória deve ser igual a 1. A melhor estimativa de $\mathrm{H}$ e $\mathrm{K}$ se dá quando as fases são empilhadas coerentemente.

\section{Resultados}

Os resultados, mostrados na tabela 1 , foram obtidos para vinte e sete estações das redes já citadas e a Figura 3 mostra um mapa topográfico de toda região acrescido do mapa de interpolação de profundidade da Moho. Podemos observar que a espessura diminui da borda oeste da Província para a borda leste, na borda sul a espessura diminui do cráton do São Francisco em direção ao planalto da Borborema, aumentando localmente na região do planalto, com uma maior profundidade sob a estação PCSA. Seguindo para o NE, a espessura diminui até a bacia Potiguar.

Semelhantemente a Figura 4 mostra a topografia acrescida da interpolação da razão $\mathrm{Vp} / \mathrm{Vs}$ em todo Nordeste Brasileiro. Em geral observamos que as razões $\mathrm{Vp} / \mathrm{Vs}$ diminuem da direção SSW para NNE, e possui um pico de 1.79 sob a estação PCBS no planalto, voltando a diminuir na direção predominante. A Figura 5 mostra o HK Stacking para duas estações de período curto e a Figura 6 mostra $\circ \mathrm{H}$-k Stacking para duas estações RSisNE.

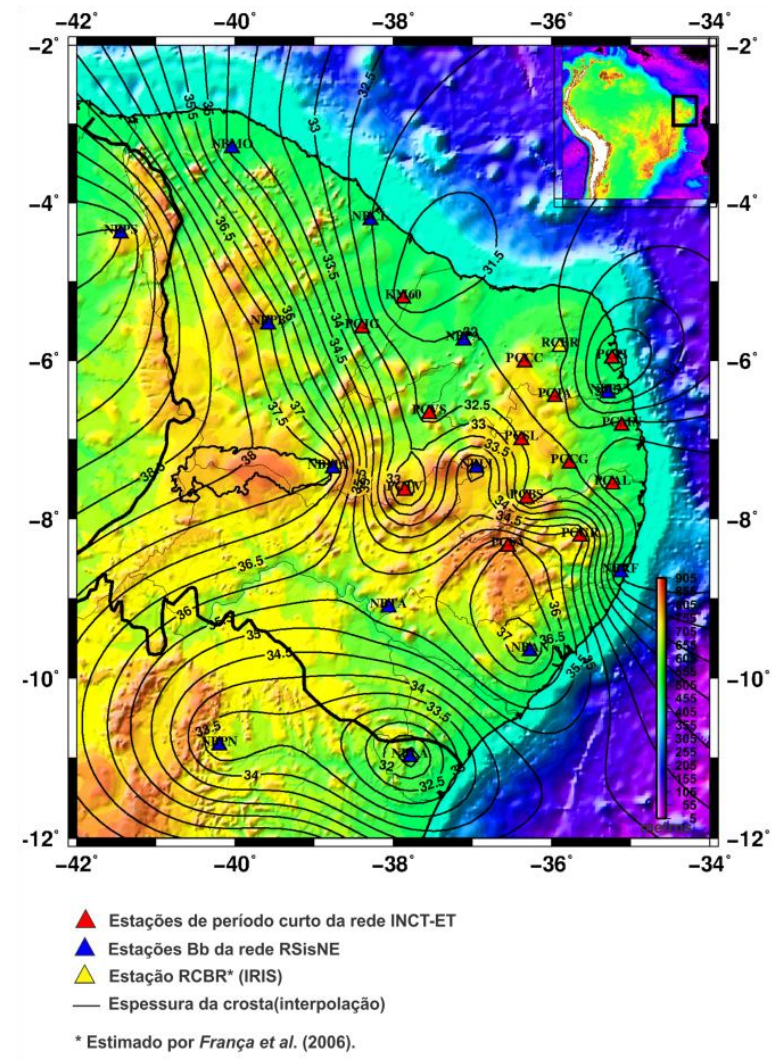

Figura 3: Mapa topográfico e de profundidade da Moho, usando resultados das estimativas obtidas pelas funções de receptor no Nordeste Brasileiro, com destaque para a região do Planalto da Borborema. 


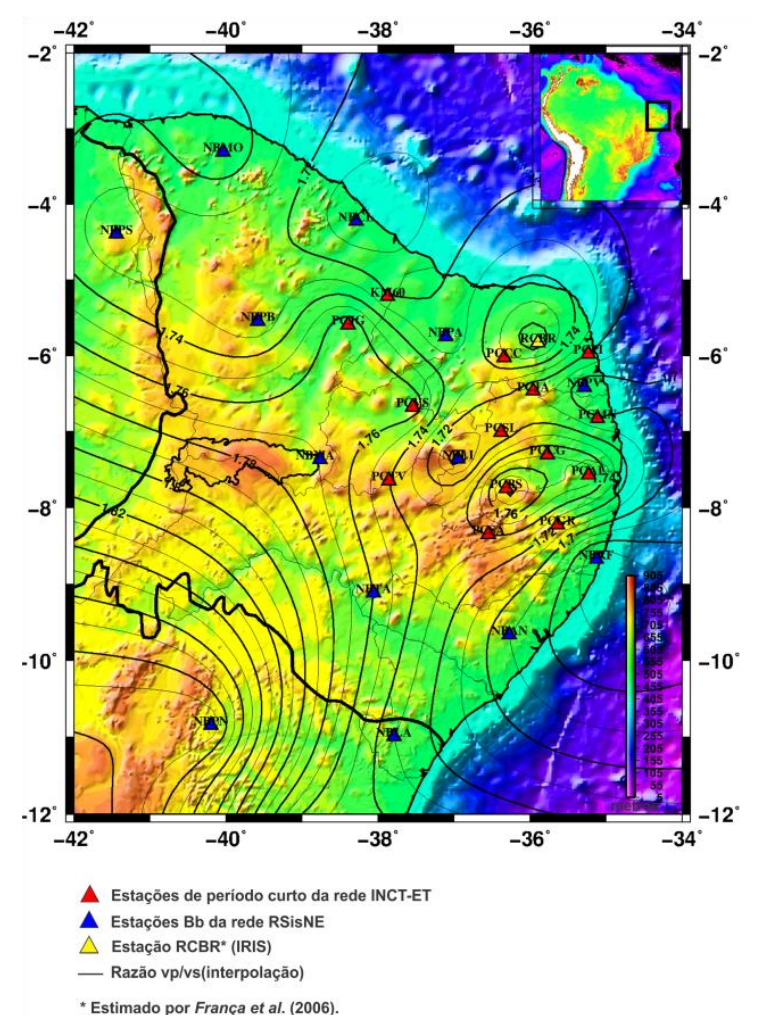

Figura 4: Mapa topográfico e da razão vp/vs, usando resultados das estimativas obtidas pelas funções de receptor no Nordeste Brasileiro, com destaque para a região do planalto da Borborema.
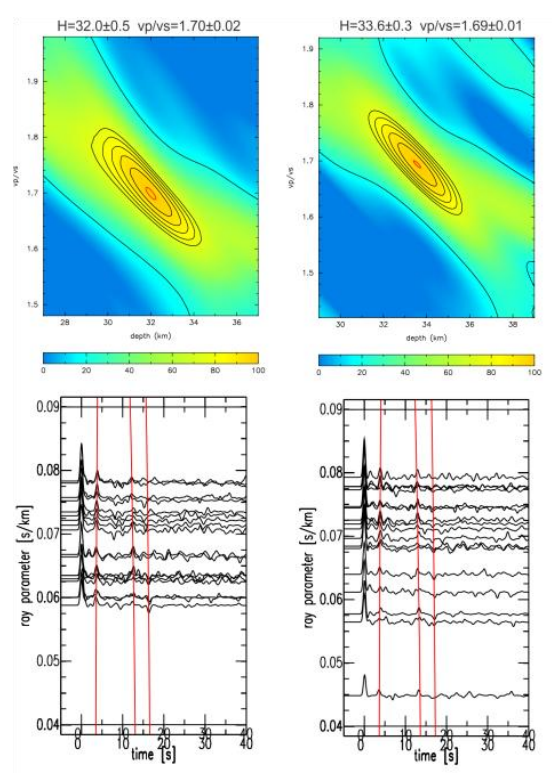

Figura 5: H-k Stacking para estações de período curto.
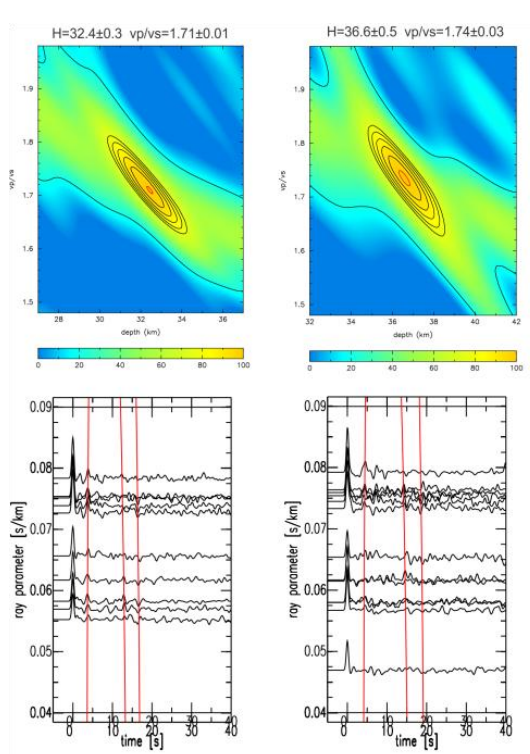

Figura 6: H-k Stacking para estações BB RSisNE.

Três perfis são mostrados nas figuras 7 a 9 . $O$ perfil 1 (Figura 7), mostra a estação PCSA instalada no centro do planalto, a estação PCBS um pouco mais afastada, com 172 metros de elevação a menos que PCSA, a estação PCCG com uma elevação menor que as primeiras e as estações NBTA e PCMN que estão localizadas fora do planalto. Observamos que sob a estação PCSA a profundidade da Moho chega a $36.6 \mathrm{~km}$ e diminui para $32.1 \mathrm{~km}$ sob PCBS, enquanto diminui para $35.9 \mathrm{em}$ NBTA. No entanto, a variação da espessura não mostra uma correlação clara com a variação da razão Vp/Vs.

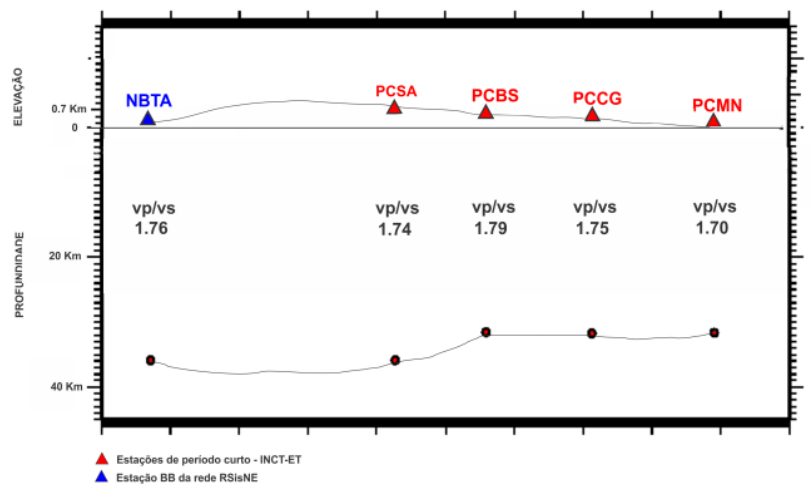

Figura 7: Perfil na direção NNE-SSW através do planalto da Borborema, estações NBTA, PCSA, PCBS, PCCG e PCMN.

O perfil 2 (Figura 8), mostra a estação NBMA localizada na região do Araripe, as estações PCSA e PCTV na região central do planalto, um pouco mais baixo, mas ainda no planalto está a estação PCGR e NBRF localizada próximo ao litoral, distante do Planalto. 


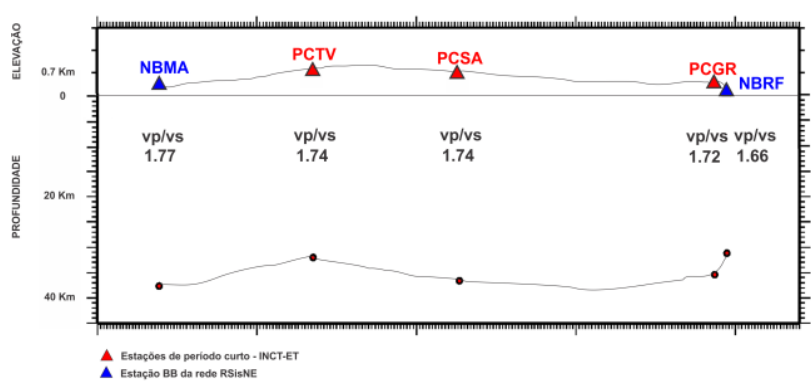

Figura 8: Perfil na direção NNW-SSE através do planalto da Borborema, estações NBMA, PCTV, PCSA, PCGR e NBRF.

O perfil 3 (Figura 9), mostra a estação PCJG localizada na região do Ceará, PCVS em uma região mais elevada, NBLI, PCBS e PCGR no planalto e NBRF distante do planalto.

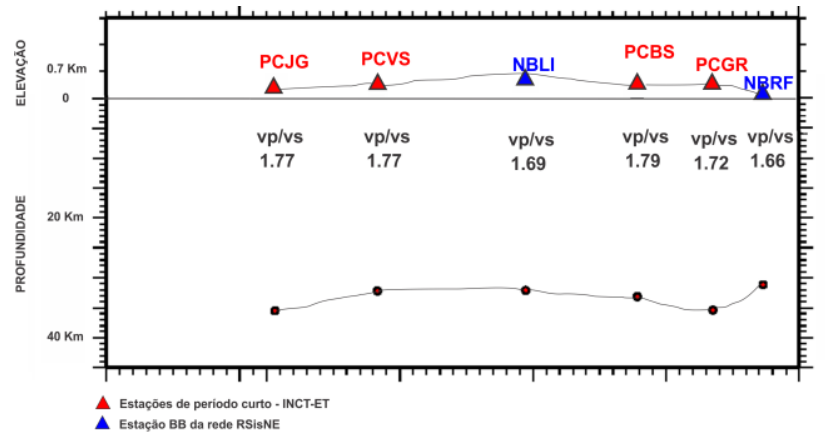

Figura 9: Perfil na direção NNW-SSE através do planalto da Borborema, estações PCJG, PCVS, NBLI, PCBS, PCGR e NBRF.

\section{Discussão e Conclusões}

Após análise das estimativas, podemos observar que na Província Borborema há uma diminuição da espessura crustal de Oeste para Leste, sem correlação com a razão Vp/Vs. Quanto a região do Planalto da Borborema, o perfil 1, orientado na mesma direção do Planalto, mostra mais claramente a presença de crosta espessa do que os perfis 2 e 3 . Mas, em geral, a análise dos três perfis mostra que existe a presença de uma crosta mais espessa na região central do Planalto comparada ao restante da Província. Embora o aumento da razão Vp/Vs com a espessura crustal não esteja tão claro, na mesma região.

O grande número de estações usadas no trabalho possibilitou melhorar as estimativas de topografia da Moho em toda região Nordeste, antes estimadas por dados gravimétricos e por funções do receptor em 5 estações sismográficas (Oliveira, 2008; Barbosa, 2008).

\section{Agradecimentos}

Ao Projeto do RSisNE (PETROBRAS-FUNPEC-UFRN), Ao Instituto Nacional de Ciência e Tecnologia - Estudos Tectônicos (INCT-ET/CNPq, projeto número
57.3713/2008-1), Ao LabSis/UFRN pelos dados concedidos. RMdN agradece ao PPGG/UFRN pela Formação e à CAPES pela bolsa concedida. AFdN, JJ e JMF agradecem ao $\mathrm{CNPq}$ pelas suas respectivas bolsas $P Q$.

\section{Referências}

Barbosa, M. F. N., 2008. Estimativa de Espessura Crustal na Província Borborema (NE/Brasil) através de Funcãoo do Receptor. Dissertação de Mestrado, Programa de Pós Graduação em Geodinâmica e Geofísica, Universidade Federal do Rio Grande do Norte.

Christensen N. I., 1996. Poisson's ratio and crustal seismology. J. geophys. Res., 101, 3139-3156.

França, G.S., Assumpção, M. \& Ferreira, J.M., 2006. O Estudo da estrutura da crosta no NE do Brasil, usando Função do Receptor. Em: II Simpósio Brasileiro de Geofísica da Sociedade Brasileira de Geofísica, Natal, 21-23 de setembro.

Julià, J., Ammom, C.J., Herrmann, R.B. \& Correig, A.M. 2000. Joint inversion of receiver function and surface wave dispersion observations. Geophys. J. Int.143, 99112.

Julià, J. \& Mejía, J. 2004. Thickness and Vp/Vs Ratio Variation in the Iberian Crust. Geophysical Journal International. 156, 59-72.

Langston, C.A., 1979. Structure under Mount Rainier, Washington, inferred from teleseismic body waves. Journal of Geophysical Research 84, 4749-4762.

Mizusaki, A.M.P., Thomas-Filho, A., Milani, P. \& Césero, P. 2002. Mesozoic and Cenozoic igneous activity and its tectonic control in Northeastern Brazil. Journal of South American Earth Sciences 15, 183-198.

Morais Neto, J. M., Hegarty, K. A., Karter, G. D. \& Alkimim, F. F., 2009. Timing and mechanisms for the generation and modification of anomalous topography of Borborema Province, northeastern Brazil, Marine and Petroleum Geology 26, 1070-1086.

Oliveira, R.G., 2008. Arcabouço Geofísico, Isostasia e causas do magmatismo Cenozóico da Província Borborema e de sua margem continental (Nordeste do Brasil). Tese de Doutorado, Programa de Pós Graduação em Geodinâmica e Geofísica, Universidade Federal do Rio Grande do Norte.

Oliveira, R. G. \& Medeiros, W. E., 2012. Evidences of buried loads in the base of the crust of Borborema Plateau (NE Brazil) from Bouguer admittance estimates. Journal of South American Earth Sciences 37, 60-76.

Zhu, L. \& Kanamori, H., 2000. Moho depth variation in southern California from teleseismic receiver function. J. Geophys.Res., 105,2969-2980. 
Tabela 1: Resultados do H-k Stacking para todas as estações.

\begin{tabular}{|c|c|c|c|c|c|}
\hline \multicolumn{6}{|c|}{ Estações INCT-ET } \\
\hline Estação & $\mathbf{H}(\mathbf{k m})$ & $\sigma(\mathbf{k m})$ & $V_{p} / V_{S}$ & $\sigma(\mathrm{km} / \mathrm{s})$ & Coeficiente de correlação(\%) \\
\hline KM60 & 36,2 & 1 & 1,75 & 0,04 & 93,7 \\
\hline PCAL & 32,5 & 1,9 & 1,69 & 0,04 & 91,3 \\
\hline PCBS & 30,4 & 0,4 & 1,74 & 0,01 & 87,4 \\
\hline PCCC & 36,5 & 0,5 & 1,72 & 0,02 & 87,7 \\
\hline PCCG & 32,1 & 0,5 & 1,75 & 0,02 & 60,6 \\
\hline PCGR & 35,4 & 1,1 & 1,72 & 0,03 & 89,4 \\
\hline PCJA & 31,7 & 1,6 & 1,71 & 0,04 & 96,7 \\
\hline PCJG & 33,1 & 0,5 & 1,77 & 0,02 & 80,3 \\
\hline PCMN & 31,7 & 0,8 & 1,7 & 0,03 & 97,2 \\
\hline PCPI & 34,3 & 2,7 & 1,72 & 0,11 & 82,7 \\
\hline PCSA & 36,6 & 0,5 & 1,74 & 0,03 & 83,7 \\
\hline PCSL & 32,4 & 0,3 & 1,71 & 0,01 & 84,2 \\
\hline PCTV & 32 & 1,3 & 1,74 & 0,05 & 86,7 \\
\hline PCVS & 35,8 & 1,1 & 1,7 & 0,03 & 90,9 \\
\hline \multicolumn{6}{|c|}{ Estações RSisNE } \\
\hline NBAN & 37,5 & 0,7 & 1,69 & 0,03 & 72,9 \\
\hline NBCL & 32 & 0,5 & 1,7 & 0,02 & 82,4 \\
\hline NBLA & 31,1 & 1,9 & 1,73 & 0,07 & 82,9 \\
\hline NBLI & 35,5 & 0,6 & 1,69 & 0,03 & 89,2 \\
\hline NBMA & 37,7 & 1,2 & 1,77 & 0,04 & 98,5 \\
\hline NBMO & 34,3 & 0,8 & 1,75 & 0,03 & 85,1 \\
\hline NBPA & 32,2 & 0,8 & 1,72 & 0,02 & 91,6 \\
\hline NBPB & 37,1 & 0,9 & 1,72 & 0,02 & 91,2 \\
\hline NBPN & 33 & 1,2 & 1,9 & 0,05 & 95,5 \\
\hline NBPS & 40,6 & 4,4 & 1,72 & 0,09 & 99,7 \\
\hline NBPV & 33,6 & 0,3 & 1,69 & 0,01 & 92,3 \\
\hline NBRF & 31,2 & 1,9 & 1,66 & 0,05 & 94,4 \\
\hline NBTA & 35,9 & 1 & 1,76 & 0,03 & 95,3 \\
\hline
\end{tabular}

